\title{
Crescimento e rendimento da cultura do trigo com aplicações de boro
}

\section{Growth and yield of wheat with boron applications}

\author{
Andressa Keli Maculan \\ Centro Universitário Fundação Assis Gurgacz \\ E-mail: andressamaculan@hotmail.com \\ OrclD: https://orcid.org/0000-0001-8305-1265 \\ Simone Marcon Bruning \\ Centro Universitário Fundação Assis Gurgacz \\ E-mail: simone.marcon@hotmail.com \\ OrcID: https://orcid.org/0000-0002-8798-2435 \\ Amanda Letícia Pit Nunes \\ Centro Universitário Fundação Assis Gurgacz \\ E-mail: amanda.pit@outlook.com \\ OrcID: https://orcid.org/0000-0002-6168-478k
}

\begin{abstract}
Resumo: A deficiência do micronutriente boro (B) se destaca pelos prejuízos relativos à formação e qualidade da colheita, sendo importante a compreensão de seu manejo e de sua aplicação no cultivo de grãos. O objetivo do estudo foi avaliar o crescimento e o rendimento da cultura de trigo em resposta a doses e formas de aplicação de boro. O estudo foi conduzido em casa de vegetação, em Cascavel, Paraná, Brasil. O delineamento experimental foi o de blocos casualizados, e os quatro tratamentos avaliados foram: testemunha sem adição de B; fertilização via sulco (octaborato de sódio 20,5\% de B, 1,0 kg.ha-1); fertilização via foliar (octaborato de sódio $2 \%$ de $\left.B, 150 \mathrm{~mL} \cdot \mathrm{ha}^{-1}\right)$ e fertilização via sulco mais foliar (1,0 kg.ha ${ }^{-1}$ de octaborato de sódio $20,5 \%$ de $B$ + foliar $150 \mathrm{~mL}$. ha-1 de octaborato de sódio $2 \%$ de B). Foram avaliados o comprimento do sistema radicular e da parte aérea, bem como massa seca da planta e rendimento de grãos. A fertilização com B via sulco e foliar proporcionou incremento de $56,5 \%$ no rendimento de grãos em relação às plantas que não receberam esse micronutriente. A aplicação de B favoreceu o crescimento e rendimento do trigo, sendo recomendada sua aplicação via sulco e via foliar na adubação da cultura.
\end{abstract}

Palavras-chave: Adubação borratada; Fertilidade do solo; Fitotecnia; Nutrição de plantas; Triticum aestivum.

\begin{abstract}
The deficiency of the micronutrient boron $(B)$ stands out for the losses related to the formation and quality of the harvest. It is essential the comprehension about $B$ fertilization and its application in the grain crops. The aim of the study was evaluating the growth and yield of wheat in response to different levels and forms of application of boron micronutrient. The experimental design was randomized blocks, and the four evaluated treatments were: control without addition of B; furrow fertilization (sodium octaborate $20.5 \%$ B, $1.0 \mathrm{~kg}^{\text {. ha }}{ }^{-1}$ ); leaf fertilization (sodium octaborate $2 \% \mathrm{~B}, 150 \mathrm{~mL} \cdot \mathrm{ha}^{-1}$ ) and furrow + leaf fertilization (1.0 kg.ha ${ }^{-1}$ sodium octaborate $20.5 \%$ B + leaf $150 \mathrm{~mL}$.ha ${ }^{-1}$ of sodium octaborate $2 \%$ of B). The lenghth of root system and aerial part, dry mass of the plant and yield of grains were evaluated. The fertilization with furrow and leaf boron provided an increment of $56.5 \%$ in the grain yield than those plants without this micronutrient application. The application of B furthered the growth and yield of the wheat, being recommended its furrow and leaf application in the fertilization of this crop.
\end{abstract}

Key words: Borate fertilization; Soil fertility; Plant breeding; Plant nutrition; Triticum aestivum. 
O trigo é o segundo cereal mais produzido do mundo, com 730.880 milhões de toneladas na safra 2018/2019. Sendo a produção nacional, para o mesmo período, de 5.532 milhões de toneladas, o que resultou na importação de 7.000 milhões de toneladas para suprir a demanda interna (FAO, 2020). Segundo a CONAB (2019), o Paraná foi o maior produtor de trigo do Brasil em 2018 (52,2 \% da produção), totalizando 2.835 milhões de toneladas.

A produtividade do trigo varia anualmente devido, principalmente, à deficiência nutricional, doenças e pragas (TAVARES et al., 2013). Além da influência das condições climáticas e das técnicas de cultivo, a qualidade das sementes usadas (MARINHO et al., 2018) e escolha de cultivar adaptada à região também influenciam o rendimento da cultura. O trigo é uma planta exigente nutricionalmente, que necessita de solo com nutrientes disponíveis para que assim, atinja elevada produção (WIETHOLTER, 2011).

O boro (B) é um micronutriente essencial ao crescimento e desenvolvimento das plantas. Diversas formas de boro podem ser encontradas no solo, com distintas disponibilidades para as plantas, sendo seus teores na solução controlados, principalmente, por reações de adsorção dependentes do pH do solo, do teor de Al (SANTOS et al., 2020) e de matéria orgânica (LEMARCHAND et al,. 2005)

O B é um dos micronutrientes que mais limita a produção de grãos nos sistemas agrícolas brasileiros (GALINDO et al., 2018a). No campo, a reprodução das plantas é afetada por baixos teores de B e reduções significativas de rendimento de grãos podem ocorrer sem sintomas visuais perceptíveis durante o crescimento vegetativo, sendo o teor adequado para o desenvolvimento das culturas bastante variável (MARSCHNER, 2012). A adequada nutrição de $B$ é preconizada para o trigo, pois afeta diretamente o rendimento da cultura ao favorecer a fertilização e germinação do grão de pólen, assim como o processo de enchimento dos grãos (DE BONA et al., 2016), sendo que a aplicação via foliar do nutriente pode melhorar o crescimento das plantas, a fecundação das flores e o número de perfilhos, resultando em aumento no rendimento de grãos (ZOZ et al., 2016).

No caso da cultura do trigo, a deficiência do micronutriente resulta em deformação e morte dos meristemas apicais, deformação das folhas novas e baixo desenvolvimento, ou deformidade das inflorescências; a deficiência ainda aumenta a esterilidade das plantas, acarretando alto número de grãos mal desenvolvidos ou chochos (DE BONA et al., 2016).

Estudos sobre a aplicação foliar de micronutrientes se mostram necessários a fim de fundamentar sua recomendação, sendo assim, o objetivo do presente estudo foi avaliar o efeito da aplicação de boro no crescimento e rendimento do trigo, por meio de níveis e formas de aplicação do microelemento.

\section{Material e Métodos}

O experimento foi conduzido em casa de vegetação, no município de Cascavel, Paraná, Brasil, localizada na latitude $24^{\circ} 53^{\prime} 59^{\prime \prime} S$ e na longitude $53^{\circ} 24^{\prime} 21^{\prime \prime} \mathrm{W}$. O clima da região, segundo a classificação de Köppen, é Cfa (subtropical úmido com verões quentes), com precipitação anual média de $1.822 \mathrm{~mm}$ e altitude média de $660 \mathrm{~m}$ (CLIMATE, 2018).

Avaliou-se o crescimento e rendimento do trigo com aplicações de boro via sulco e foliar, utilizando vasos de $4 \mathrm{~kg}$ para o cultivo. Foram semeadas 10 sementes por vaso e, posteriormente, após a emergência realizou-se o desbaste de plantas excedentes para obtenção de população de 4 plantas por vaso (Brunes et al., 2015). A cultivar utilizada foi a Tbio Toruk® da Biotrigo Genética, de estatura baixa, perfilhamento e espigamento uniformes e boa resistência ao acamamento. A cultivar demanda alta tecnologia e fertilidade, mas possui altos níveis produtivos potenciais, além de característica de trigo pão/melhorador, com alta qualidade industrial (BIOTRIGO, 2020). A semeadura foi realizada no dia 24 de maio 2018. A umidade gravimétrica do solo nos vasos foi mantida a $70 \%$ da capacidade máxima de retenção de água do solo.

O solo utilizado no presente estudo foi classificado como LATOSSOLO VERMELHO Distrófico (SANTOS et al., 2018), sendo peneirado em malha de $4 \mathrm{~mm}$ antes do preenchimento dos vasos e, caracterizado por meio de análise química do solo (Donagema et al., 2011) antes da semeadura, conforme Tabela 1.

O delineamento experimental utilizado foi o inteiramente casualizado, composto por 4 tratamentos e 5 repetições, sendo Testemunha: sem aplicação de $B$, Sulco: Octaborato via sulco $(1,0 \mathrm{~kg}$.ha-1 de octaborato de sódio), Foliar: Octaborato via foliar $\left(0,4 \mathrm{~kg} \cdot \mathrm{ha}^{-1}\right.$ de octaborato - $150 \mathrm{~mL}$ de calda) e Sulco + Foliar: Octaborato 
via sulco e foliar (1,0 kg.ha-1 de octaborato + foliar 0,4 kg.ha-1 $-150 \mathrm{~mL}$ de calda). Sendo a fonte octaborato de sódio usada por sua alta concentração do micronutriente e solubilidade em água.

Tabela 1. Caracterização química do solo utilizado no cultivo do trigo.

\begin{tabular}{|c|c|c|c|c|c|c|c|c|c|c|c|c|c|}
\hline $\mathbf{P}$ & MO & $\mathrm{pH}$ & $\mathrm{H}+\mathrm{Al}$ & $\mathrm{Al}^{+3}$ & $\mathrm{Ca}^{+2}$ & $\mathbf{M g}^{+2}$ & $\mathrm{~K}^{+}$ & $\mathrm{CTC}_{\mathrm{pH} 7,0}$ & $\mathbf{V}$ & Areia & Silte & Argila & B \\
\hline $\mathrm{mg} \mathrm{dm}^{-3}$ & $\mathrm{~g} \cdot \mathrm{dm}^{-3}$ & $\mathrm{CaCl}_{2}$ & - & ------ & $---\mathrm{cmc}$ & c. $\mathrm{dm}^{-3}$ & . & ------- & $\%$ & & $--g \cdot \mathrm{kg}^{-1}$ & ---- & mg.dm 3 \\
\hline 18.60 & 43.00 & 5.1 & 3.97 & 0.00 & 9.85 & 2.31 & 0.61 & 16.74 & 76.28 & 175 & 137.5 & 687.5 & 0.54 \\
\hline
\end{tabular}

Extratores: Mehlich $\left(\mathrm{P}, \mathrm{K}^{+}\right) ; \mathrm{KCl} 1 \mathrm{~N}\left(\mathrm{Ca}^{+2}, \mathrm{Mg}^{+2}, \mathrm{Al}^{+3}\right)$; M.O.: Matéria orgânica; CTC: Capacidade de troca catiônica a pH 7,0; V: Saturação por bases.

A fonte de $B$ utilizada via sulco foi o octoborato de sódio, com $20,5 \%$ de $B$, enquanto a fonte usada na adubação foliar apresenta $2,0 \%$ de $\mathrm{B}$. A adubação de base no sulco de semeadura foi proporcional à de $80 \mathrm{~kg}$ ha-1 do adubo 10-15-15 (N- $\left.\mathrm{P}_{2} \mathrm{O}_{5}-\mathrm{K}_{2} \mathrm{O}\right)$, segundo recomendações para a cultura do trigo na região (EMBRAPA, 2017). Não se realizou a aplicação de calcário.

As adubações complementares com B foram realizadas 60 dias após o plantio, na fase de frutificação, de acordo com os tratamentos descritos acima. As aplicações foram realizadas com pulverizador costal manual com capacidade de pressão de trabalho de 0,6 MPa, equipado com ponta do tipo jato cone vazio, calibrado para aplicação de $200 \mathrm{~L} \mathrm{ha}^{-1}$ de calda.

Quando observada a presença de plantas indesejadas, elas foram arrancadas manualmente no início de seu desenvolvimento. Não houve incidência de pragas e doenças durante a condução do ensaio em casa de vegetação. A colheita manual foi realizada no estádio em que dois terços das espigas apresentavam coloração marrom, 148 dias após o plantio. Para a avaliação do sistema radicular, as plantas foram retiradas cuidadosamente, sendo o excesso de terra retirado em água corrente. As variáveis avaliadas foram: (i) comprimento radicular e, (ii) comprimento da parte aérea ao final do ciclo vegetativo, com o ajuda de uma trena; (iii) massa seca de plantas, após medição as plantas foram secas em estufas de circulação de ar forçada à $70^{\circ} \mathrm{C}$ até peso constante; (iv) número de espigas por contagem manual em cada unidade experimental; e (v) massa de sementes por planta, obtida pela pesagem das sementes colhidas, sendo a umidade corrigida para 13\% (BRASIL, 2009).

Os dados foram testados para normalidade e homogeneidade da variância dos resíduos e, submetidos à análise de variância. As médias foram comparadas pelo teste de Tukey a $5 \%$ de probabilidade, no programa estatístico Minitab® Statistical Software (MINITAB INC., 2010).

\section{Resultados e Discussão}

Em relação ao comprimento da raiz, observa-se maior crescimento nos tratamentos em que houve aplicação do B, independente da forma e da dose (Tabela 2). Corrobora os resultados de Araujo et al. (2016), que também observaram comprimento maior de raízes de trigo com a aplicação de $B$ via tratamento de sementes. Resultados distintos foram observados por Brunes et al. (2016) e Fageria (2000), que não constataram efeito do B no comprimento de raízes da mesma cultura. Entretanto, Fageria (2000) observou que o trigo foi mais eficiente no uso de $B$, para crescimento, que feijão e soja; mas também apresentou sistema radicular mais sensível a valores altos do micronutriente, sendo menos tolerante à toxidez por $B$ que feijão, soja, arroz e milho.

Tabela 2. Comprimento das raízes e da parte aérea do trigo ao final do estádio vegetativo submetidos a aplicações com boro.

\begin{tabular}{lcc}
\hline Tratamento & $\begin{array}{c}\text { Comprimento raiz } \\
\mathbf{c m}\end{array}$ & $\begin{array}{c}\text { Comprimento parte aérea } \\
\mathbf{c m}\end{array}$ \\
\hline Testemunha & $12,38 \mathrm{~b}$ & $53,30 \mathrm{~b}$ \\
Sulco & $16,52 \mathrm{a}$ & $57,58 \mathrm{ab}$ \\
Foliar & $18,80 \mathrm{a}$ & $60,44 \mathrm{a}$ \\
Sulco + Foliar & $19,52 \mathrm{a}$ & $55,98 \mathrm{ab}$ \\
\hline
\end{tabular}


Médias com mesma letra, não diferem entre si, pelo teste de Tukey a $5 \%$ de probabilidade. CV\% = Coeficiente de Variação. Médias com mesma letra, não diferem entre si, pelo teste de Tukey a $5 \%$ de probabilidade. $\mathrm{CV} \%=1,88$.

Ainda na Tabela 2, observam-se os dados referentes ao comprimento da parte aérea da cultura do trigo, sendo que o tratamento foliar obteve maior crescimento, quando comparado aos outros tratamentos. Dados semelhantes foram verificados por Brunes et al. (2016) para a cultivar FUNDACEP Horizonte, em que houve maior comprimento da parte aérea em plantas adubadas com $B$ na semeadura e 15 dias após a floração. Zoz et al. (2016) verificaram que a aplicação foliar conjunta de B e Ca no trigo, em solos com menor disponibilidade de $\mathrm{B}\left(0,25 \mathrm{mg} \mathrm{B} \mathrm{dm}^{-3}\right)$ melhorou o crescimento, a fecundação das flores e o número de perfilhos, resultando em maior rendimento de grãos em relação ao tratamento controle.

A aplicação no sulco somada à via foliar (Sulco + Foliar) demonstrou-se superior no acúmulo de massa seca pelas plantas de trigo (Figura 1). Para essa variável, a adubação via foliar (Foliar) apresentou resultado semelhante à testemunha, sendo a adubação no sulco de plantio (Sulco) o tratamento intermediário. Araujo et al. (2016) verificaram variação à resposta da massa seca da parte aérea e raiz pela adubação de boro dependendo da fonte do micronutriente e da cultivar do trigo, havendo maior massa seca principalmente com a adição de ácido bórico.

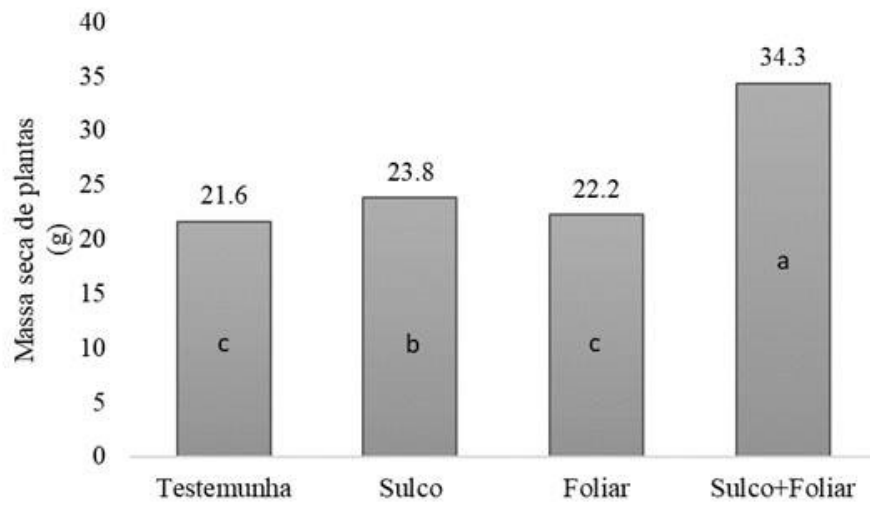

Figura 1. Massa seca da parte aérea e raízes das plantas de trigo ao final do estádio vegetativo

Todos os tratamentos fertilizados com B apresentaram produção superior à testemunha (Tabela 3). Maiores números de espigas foram verificados com aplicação de B via Foliar e via Sulco + Foliar, sendo superior a produção no tratamento Sulco + Foliar $\left(9,58 \mathrm{~g} \mathrm{vaso}^{-1}\right)$. O boro desempenha um papel vital no estabelecimento de grãos de trigo. Portanto, o seu suprimento favorece o enchimento de grãos, sendo a esterilidade reduzida e número de grãos por espiga aumentado (TAHIR et al., 2009). O número de espigas e o número de grãos estão diretamente relacionados com o rendimento da cultura.

A produção por planta foi superior nas plantas que receberam adubação boratada via Sulco + Foliar. Os resultados observados corroboram Zoz et al. (2016) e Tahir et al. (2009) que demonstraram que a fertilização adequada com B promoveu melhor desenvolvimento e produtividade do trigo. O maior rendimento da cultura é justificado pelo favorecimento da germinação do tubo polínico e o estabelecimento das espigas, principalmente pela aplicação do micronutriente próximo à fase de desenvolvimento dos órgãos sexuais masculinos da planta (TAHIR et al., 2009). Entretanto, Brunes et al. (2016) não observaram aumento de rendimento de sementes por planta pela aplicação de B em diferentes épocas do desenvolvimento da cultura, Tavares et al. (2013) também não observaram incremento produtivo na cultura do trigo ao usar doses de $\mathrm{B}$ associadas a outros micronutrientes.

Apesar do teor adequado de B no solo (Tabela 1), considerado médio para a cultura, verificou-se resultado positivo da adubação no rendimento da cultura. O oposto foi verificado por Enderson et al. (2015), que com nível adequado de $B$ no solo não verificaram resultado da adubação foliar com o micronutriente. Tahir et al. (2009) também verificaram rendimento superior de trigo com a aplicação foliar de B, mas em solo com teor baixo do micronutriente. Galindo et al. (2018a) também verificaram resultado positivo no rendimento da cultura do trigo com o aumento da dose de adubo boratado até a dose de $2 \mathrm{~kg} \mathrm{ha}^{-1}$, dose recomendada ao final do estudo para essa cultura. Estudos relataram sintomas da deficiência de $\mathrm{B}$ em trigo independentemente do teor de B extraído do solo (KATAKI et al., 2002; RASHID et al., 2002), e em estudo com diferentes doses e 
formas de aplicação de B em trigo, Galindo et al. (2018b) demonstraram que, mesmo em solos com boas reservas do micronutriente, a adubação boratada pode aumentar o rendimento da cultura, pois, além da maior demanda de B para a formação das sementes que para o desenvolvimento vegetativo da planta, em solos tropicais é menor a presença de matéria orgânica, grande fonte do micronutriente.

Tabela 3. Número de espigas e rendimento da cultura de trigo.

\begin{tabular}{lcc}
\hline Tratamento & Número de espigas por planta & Produção por planta (g) \\
\hline Testemunha & $3,64 \mathrm{c}$ & $6,12 \mathrm{~d}$ \\
Sulco & $4,30 \mathrm{bc}$ & $7,40 \mathrm{c}$ \\
Foliar & $5,44 \mathrm{a}$ & $8,72 \mathrm{~b}$ \\
Sulco + Foliar & $5,72 \mathrm{a}$ & $9,58 \mathrm{a}$ \\
\hline CV\% & 13,44 & 2,14
\end{tabular}

Médias com mesma letra, não diferem entre si, pelo teste de Tukey a $5 \%$ de probabilidade. CV\% = Coeficiente de Variação.

O tratamento com fertilização via sulco e foliar (Sulco + Foliar) apresentou rendimento 56,5\% superior à testemunha e 10,2\% superior ao tratamento Foliar. Entretanto, os custos operacionais com fertilizantes para o trigo, no Paraná, podem representar entre 26 e 37,5\% do custo total (CONAB, 2018; MAGGIAN et al., 2009), por isso, os custos dos fertilizantes e da aplicação devem ser considerados para avaliar a viabilidade de uma adubação adicional na cultura.

Segundo Bona et al. (2016), o trigo deve receber fornecimento adequado de B, pois afeta diretamente o rendimento da cultura ao favorecer a fertilização e germinação dos grãos de pólen, que, por sua vez, atuam diretamente no enchimento de grãos aumentando, consequentemente, o número e massa de grãos. Verificouse a superioridade no número de espigas para a aplicação do micronutriente via Foliar e via Sulco + Foliar, sendo que somente o último tratamento refletiu em maior rendimento de grãos. A partir dos resultados obtidos, recomenda-se a fertilização do trigo com B via sulco e foliar, pois, promoveu maior crescimento radicular e da parte aérea, assim como resultou em maior rendimento da cultura, quando comparada à fertilização somente via sulco ou via foliar.

Os custos dessa prática foram levantados, atingindo as somas, por hectare, de $R \$ 15,00, R \$ 43,20$ e $\mathrm{R} \$ 58,20$ para a aplicação do micronutriente via Sulco, via Foliar e via Sulco + Foliar, respectivamente para a região do estudo, considerando o produto e a operação realização além do plantio. No caso das formas de aplicação estudadas, a via sulco não apresenta acréscimo de operação agrícola, e aplicação via foliar muitas vezes é realizada no momento da aplicação de outros produtos na área cultivada, o que poderia reduzir o custo da aplicação. Ainda assim, mais estudos devem ser realizados a fim de se averiguar a viabilidade econômica da aplicação via foliar, como na extensão do presente estudo às condições de campo, para verificar o incremento obtido em área agrícola e a compatibilidade com outras operações agrícolas, bem como sua eficácia em comparação com outras fontes do micronutriente.

Apesar disso, verificou-se efeito positivo da adubação boratada na cultura do trigo, mesmo em teor adequado do micronutriente no solo. A partir dos resultados de rendimentos, sugere-se, a partir dos custos de cada forma de aplicação, que a fertilização boratada via Sulco + Foliar seja usada, sendo uma estratégia de adubação importante para favorecer a sustentabilidade da produção da cultura no estado do Paraná, pois resultou em incremento de 56,5 \% no rendimento em condição de casa de vegetação.

\section{Conclusões}

As plantas fertilizadas com $B$ apresentaram maior crescimento de raízes e da parte aérea. Maior massa seca foi verificada para as plantas que receberam a adubação boratada via Sulco e via Sulco + Foliar. O número de espigas foi superior para as plantas que receberam o micronutriente via Foliar e via Sulco + Foliar, e a produção de grãos foi maior para todos os tratamentos fertilizados com B. A aplicação do micronutriente via Sulco + Foliar resultou em produção de grãos $56,5 \%$ superior à testemunha.

\section{Referências}

ARAUJO, M.M.V.; SOUSA, J.R.; CAMILI, E.C. Germinação de sementes de trigo tratadas com zinco e boro. Revista de Agricultura, v.91, n.3, p. 274 - 284, 2016. 
BIOTRIGO. Biotrigo genética, 2020. Cultivares. Disponível em: < http://biotrigo.com.br/cultivares/portfolio/tbio_toruk/32>. Acesso em: 02 de jul. de 2020.

DE BONA, F.; MORI, C.; WIETHOLTER, S. Manejo nutricional da cultura do trigo. Encarte Técnico. Informações Agronômicas, n.154, 2016.

BRASIL. MINISTÉRIO DA AGRICULTURA, PECUÁRIA E ABASTECIMENTO. Regras para análise de sementes. Ministério da Agricultura, Pecuária e Abastecimento. Secretaria de Defesa Agropecuária. Brasília, DF: Mapa/ACS. 395p. 2009.

BRUNES, A.P; OLIVEIRA, S.; LEMES, E.S.; TAVARES, L.C.; GEHLING, V.M.; DIAS, L.K.; VILLELA, F.A. Adubação boratada e produção de sementes de trigo. Ciência Rural, v. 45, n. 9, p. 1572-1578, 2015.

BRUNES, A.P.; LEMES, E.S.; MENDONÇA, A.O.; OLIVEIRA, S.O.; VILLELA, F.A. Suplementação de boro em diferentes épocas: efeito no rendimento e na qualidade de sementes de trigo. Revista Verde de Agroecologia e Desenvolvimento Sustentável, v. 11, n. 2, p. 05-10, 2016.

CLIMATE. Clima: Cascavel. Disponível em: < https://pt.climate-data.org/america-do-sul/brasil/parana/cascavel5965/> Acesso em: 09 de setembro de 2018.

CONAB - COMPANHIA NACIONAL DE ABASTECIMENTO. Acompanhamento da safra brasileira: grãos. V.6 Safra 2018/19 - Sétimo levantamento, Brasília, p. 1-119, 2019.

CONAB - COMPANHIA NACIONAL DE ABASTECIMENTO. A Cultura do Trigo: análise dos custos de produção e da rentabilidade nos anos-safra 2009 a 2017. In: Compêndio de estudos Conab, v.15, 2018. Disponível em: https://www.conab.gov.br/institucional/publicacoes/compendio-de-estudos-daconab/item/download/20148 ba43e23421f262fc476c89bda17a0f97. Acesso em: 01 de fevereiro de 2019.

DONAGEMA, G.K.; CAMPOS, D.V.B. de; CALDERANO, S.B.; TEIXEIRA, W.G.; VIANA, J.H.M. Manual de métodos de análise de solo. Rio de Janeiro: Embrapa Solos. 2011. 230 p.

EMBRAPA - Empresa Brasileira de Pesquisa Agropecuária. Informações técnicas para trigo e triticale safra 2017 / X Reunião da Comissão Brasileira de Pesquisa de Trigo e Triticale; SILVA, S.R.; BASSOI, M.C.; FOLONI, J.S.S., eds- Brasília, DF: Embrapa, 2017. 240 p

ENDERSON, J.T.; MALLARINO, A.P.; HAQ, M.U. Soybean Yield Response to Foliar-Applied Micronutrients and Relationships among Soil and Tissue Tests. Agronomy Journal, v.107, n.6, 2015.

FAGERIA, N.K. Níveis adequados e tóxicos de boro na produção de arroz, feijão, milho, soja e trigo em solo de cerrado. Revista Brasileira de Engenharia Agrícola e Ambiental, v.4, n.1, p.57-62, 2000.

FAO - FOOD AND AGRICULTURE ORGANIZATION OF THE UNITED STATES. Market Summary: Wheat (AMIS Statistics Source: FAO-AMIS). Disponível em: http://statistics.amis-outlook.org/data/index.html\#. Acesso em: 05 de julho de 2020.

GALINDO, F.S.; TEIXEIRA FILHO, M.C.M.; BUZETTI, S.; BOLETA, E.H.M.; RODRIGUES, W.L.; ROSA, A. Do the application forms and doses of boron affect wheat crops? Revista Brasileira de Engenharia Agrícola e Ambiental, v.22, n.9, p. 597-603, 2018a.

GALINDO, F.S.; TEIXEIRA FILHO, M.C.M.; BUZETTI, S.; RODRIGUES, W.L.; BOLETA, E.H.M.; SANTINI, J.M.K; PEREIRA, M.R.A. Effects of Boron (B) doses and forms on boron use efficiency of wheat. Australian Journal of Crop Science, v. 12, n. 9, p. 1536-1542, 2018b.

KATAKI, P.K.; SRIVASTAVA, S.P.; SAIFUZZAMAN, M.; UPRETI, H.K. Sterility of wheat and response of field crops to applied boron in the Indo-Gangetic Plains. Journal of Crop Production, v. 4, p. 133-165, 2002.

LEMARCHAND, E.; SCHOTT, J.; GAILLARDET, J. Boron isotopic fractionation related to boron sorption on humic acid and the structure of surface complexes formed. Geochimica et Cosmochimica Acta, v. 69, p. 35193533. 2005.

MAGGIAN, R.C.; RIBEIRO, R.G.; FELIPE, F.I. Análise da rentabilidade da cultura de trigo na região de Guarapuava (PR). In: $48^{\circ}$ CONGRESSO SOBER - SOCIEDADE BRASILEIRA DE ECONOMIA, 
ADMINISTRAÇÃO E SOCIOLOGIA RURAL, 2009, Campo Grande. Anais. Disponível em: http://www.sober.org.br/palestra/15/534.pdf. Acesso em: 01 de fevereiro de 2019.

MARINHO, J.L.; BAZZO, J.H.B.; CARDOSO, C.P.; ZUCARELI, C.; FONSECA, I.C.B. produtividade e qualidade fisiológica de sementes de cultivares de trigo em diferentes densidades de semeadura. Colloquium Agrariae, v. 14, n.3, p. 122-131, 2018.

MINITAB INC. Getting Started with Minitab 18. 2010.

RASHID, A.; MUHAMMAD, S.; RAFIQUE, E. Gynotypic variation in boron uptake and utilization in rice and wheat. In: GOLDBACH, H.E.; RERKASEM, B.; WIMMER, M.A.; BROWN, P.H.; THELLIER, M.; BELL, R.W. All Aspects of Plant and Animal Boron Nutrition. Kluwer and Plenum Academic Publishers, pp. 305-310, 2002.

SANTOS, P.; GOLDBERG, S.; COSTA, A. C. S. Modeling boron adsorption on five soils before and after removal of organic matter. Scientia Agricola, v. 77, n.4, e20180023. 2020.

SANTOS, H.G.; JACOMINE, P.K.T.; ANJOS, L.H.C.; OLIVEIRA, V.A.; LUMBRERAS, J.F.; COELHO, M.R.; ALMEIDA, J.A.; ARAUJO FILHO, J.C.; OLIVEIRA, J.B.; CUNHA, T.J.F. Sistema Brasileiro de Classificação de Solos. Brasília, DF: Embrapa, 5. ed. rev. e ampl. 2018.

TAHIR, M.; TANVEER, A.; SHAH, T.H.; FIAZ, N.; WASAYA, A. Yield response of wheat (Triticum aestivum L.) to boron application at different growth stages. Pakistan Journal of Life and Social Sciences, v.7, n.1, p.3942, 2009.

TAVARES, L.C.; RUFINO, C.A.; BRUNES, A.P.; FRIEDRICH, F.F.; BARROS, A.C.S.A.; VILLELA, F.A. Physiological performance of wheat seeds coated with micronutrients. Journal of Seed Science, v. 35, n. 1, p. 28-34, 2013.

WIETHOLTER, S. Fertilidade do solo e a cultura do trigo no Brasil. In: PIRES, J.L.F.; VARGAS, L.; CUNHA, G.R. (Ed.). Trigo no Brasil: bases para produção competitiva e sustentável. Cap. 6, p. 135-184. Passo Fundo: Embrapa Trigo, 2011.

ZOZ, T.; STEINER, F.; SEIDEL, E.P; CASTAGNARA; D.D; SOUZA, G.E. Foliar application of calcium and boron improves the Spike fertility and yield of wheat. Bioscience Journal, v. 32, n.4, p. 873-880, 2016. 